\title{
COLEGIALES RIOJANOS EN EL COLEGIO MAYOR DE SANTA CRUZ DE VALLADOLID. SIGLOS XV-XVIII
}

\author{
Cristina González Caizán* \\ Universidad de Varsovia. Polonia
}

\begin{abstract}
El objetivo de este artículo no es presentar un estudio del Colegio Mayor de Santa Cruz de Valladolid sino ofrecer el cursus honorum de aquellos colegiales riojanos que pasaron por la mencionada institución'. Según un estudio de María de los Ángeles Sobaler Seco², del total de 821 colegiales de la diócesis de la Corona de Castilla durante la Edad Moderna, 115 pertenecieron a la diócesis de Calahorra-Santo Domingo de la Calzada y 5 a la de Burgos-Calahorra. Para este trabajo, nos hemos servido de aquellos colegiales cuyo origen geográfico corresponde con los límites geográficos de la actual provincia de La Rioja, lo que suma un total de 74 alumnos a lo largo de cuatro siglos. La fuente utilizada para la trascripción de los currículos ha sido el manuscrito 22, sección 8a , del Archivo del referido Colegio de Santa Cruz de Valladolid.
\end{abstract}

\section{Características de los colegiales riojanos en el Colegio Mayor de Santa Cruz de Valladolid}

Siguiendo a Isabel Perdás, quien a su vez se basó en el trabajo de Dámaso de Lario sobre el Colegio Mayor de San Clemente de Bolonia ${ }^{3}$, señalamos a con-

* Centro de Estudios sobre la Tradición Antigua en Polonia y Europa Centro-Oriental (OBTA) de la Universidad de Varsovia (UW).

1. Sobre la historia general del Colegio de Santa Cruz, funcionamiento, normativa, colegiales y otras peculiaridades véase PERDÁS GARCÍA, I., "Los Colegiales Mayores de Santa Cruz de Valladolid, 1660-1785. Estudio sociológico", en Investigaciones Históricas, Valladolid, (4) 1983, pp. 125-158.

2. SOBAler SECO, M. A., Catálogo de Colegiales del Colegio Mayor de Santa Cruz de Valladolid (1484-1786), Valladolid, 2000.

3. LARIO, D., Sobre los orígenes del burócrata moderno. El Colegio de San Clemente de Bolonia durante la impermeabilización habsburguesa (1568-1659), Bolonia, 1980. Citado por PERDÁS GARCíA I., "Los Colegiales Mayores de Santa Cruz de Valladolid, 1660-1785...", p. 128. 
tinuación las condiciones indispensables para entrar en el Colegio Mayor de Santa Cruz de Valladolid:

- ser español, considerando España el territorio comprendido entre los Pirineos y los dos mares;

- ser hijo legítimo y de cristianos viejos;

- tener 21 años de edad;

- no tener una renta anual superior a 30 ducados de oro;

- poseer el título de bachiller en Derecho, algún estudio general o haber estudiado en alguna Universidad;

- llevar algún título de presentación o carta firmada por la persona o entidad que proponía al colegial como tal;

El método expositivo seguido en el manuscrito 22 es siempre el mismo:

- nombre y procedencia del colegial;

- fecha de su ingreso en el Colegio;

- vacante que vino a ocupar;

- facultad a la que se dedicó y grados alcanzados en ella;

- oficios y dignidades obtenidas;

- pertenencia a alguna Orden Militar;

- escritos y fundaciones que pudo dejar;

- fecha de su fallecimiento y mandas dejadas al Colegio en su testamento.

En la presente transcripción se ha mantenido este orden, aunque el estilo puede aparecer alterado en función de lograr una mayor agilidad y comodidad de lectura. Los ingresos en el Colegio dependían de las vacantes, del número y de la clase de becas. Éstas podían ser de Teología (T), Cánones (C), Leyes (L), Médicas (M) y Juristas (J). Para el total de colegiales riojanos hemos contabilizado cincuenta y siete becas repartidas de la siguiente manera: Cánones (26), Teología (22), Cantadas (4), Medicina (2), Juristas (1) y sin especificar (2).

En un principio la edad del colegial no se especificaba. La media de los colegiales riojanos rondó en torno a los 25 años. El colegial más joven, Benito García y Miranda, ingresó con 19 y el mayor, Gaspar Melgar y Moreda, con 41 años. Algunos de los colegiales riojanos Ilegaron al Colegio de Santa Cruz procedentes de otros colegios mayores. Por ejemplo, Tomás Aztiguita lo hizo del de Santo Tomás de Salamanca; Diego Martín, del de Santa María de Salamanca; Martín de Rueda, Pedro Argaiz, Juan Díez Orozco y Juan de Manzanares, del Colegio Mayor de San Antonio de Sigüenza; José González de Tejada, Andrés Angulo, Antonio Bergado, José Duro del Sar, Francisco Javier Sánchez Cabezón, Manuel Segura y Castro y José Antonio Blanco, del Colegio 
Mayor de la Madre de Dios de los Teólogos de Alcalá. Tan solo tres colegiales llegaron al Colegio con alguna cátedra: Martín de Rueda, en Filosofía; Juan Díaz Orozco, en Artes y Teología y Juan de Manzanares, en Artes y doctor en Teología. La pertenencia de los colegiales riojanos a cualquiera de las cuatro Órdenes Militares es muy limitada. Únicamente Alonso de San Vicente y Velandía, Martín Castejón, Marcos Sánchez Salvador y Pedro Angulo y Velasco, en la de Calatrava y Pedro Antonio Medrano y Eháuz en la de Alcántara, logran alguna representatividad.

Un mayor número de colegiales ejercieron de rectores del Colegio de Santa Cruz. El rector era un colegial que ejercía el control sobre varias actividades. Él era quien, ayudado por dos o tres consiliarios, Ilevaba el gobierno del Colegio, todos los asuntos referidos a la provisión de becas, cargos y oficios, etc. Este cargo se podía conseguir bien en propiedad o bien en régimen de sustitución. Durante la estancia en el Colegio se podía ejercer en más de una ocasión si así lo votaban los alumnos. También existía el cargo de vicerrector, encargado de sustituir al rector en sus ausencias. De todos los colegiales riojanos lograron serlo en propiedad un total de diecisiete.

Los puestos en la enseñanza sólo se concedían a los que poseían grados avanzados, por lo tanto la mayoría de las cátedras estuvieron cubiertas por colegiales. Las cátedras se agrupaban en dos tipos: las de Derecho Canónico (Prima, Decreto, Vísperas, Sexto, Clementinas) y Derecho Civil (Prima, Vísperas, Digesto Viejo, Volumen, Código, Instituta). Muchos colegiales riojanos ocuparon más de una o dos cátedras (Tabla I).

\section{TABLA I}

Cátedra de Artes

Número de colegiales:

Cátedra de Cánones (Derecho Canónico)

Prima leyes:

1

Decreto:

10

Vísperas:

Sexto:

5

4

Clementinas:

Cánones (s.e.):

6

3

Otras cátedras

De Prima de Teología:

De Suárez:

De San Anselmo:
Cátedra de Leyes (Derecho Civil)

Prima leyes: 1

Digesto: 6

Código: $\quad 11$

Instituta: $\quad 6$

De Durando: 2

De Santo Tomás: 1

De Biblia: 1 


\section{Destino de los colegiales riojanos tras el abandono del Colegio Mayor de Santa Cruz}

Muy pocos colegiales riojanos pasaron después de su estancia en el Colegio a trabajar en la Administración, tan solo quince lograron alguna plaza en las Cancillerías o Audiencias de Valladolid y Granada. A otros encontramos en el Tribunal de la Inquisición y en la Iglesia. Lograron ocupar algún puesto en el Tribunal un total de once, alcanzando uno de ellos, Martín Castejón, la presidencia del Tribunal de Valladolid en 1662. En cuanto a cargos de Iglesia, siempre refiriéndonos a cargos de salida y teniendo en cuenta que algunos colegiales ocuparon varios, contabilizamos 11 canónigos; 8 canónigos penitenciarios; 4 priores; 5 prebendas magistrales; 3 prebendas doctorales; 2 provisores; 2 arcedianos; 1 visitador y 1 vicaría. Llegaron a ser obispos 4 colegiales riojanos; 2 lo fueron de Segovia: Andrés de Angulo en 1685 y Manuel Murillo y Argaiz en 1752. El tercero, Francisco Javier Pérez, lo fue de Teruel en 1755 y Cayetano Martínez Isunza Sánchez Salvador, de Ávila en 1766.

\section{Expedientes de colegiales riojanos conservados en el Archivo del Palacio de Santa Cruz de Valladolid}

YANGUAS, Diego de

Natural de Yanguas. Ingresó en el Colegio el 24 de febrero de 1489 (T). Licenciado en Teología. Fue canónigo de Coria. Permaneció en el Colegio dos años. Número de colegial (en adelante N. c.), 2.

FONCEA, Juan de

[Natural de Foncea]. Ingresó en el Colegio el 24 de enero de 1484 (C). Se doctoró en Decretos (1489) y formó parte del Colegio de la Gobernación del Arzobispado de Toledo (1498) de donde luego fue canónigo y más tarde inquisidor en Barcelona. Estuvo en el Colegio cinco años, poco más o menos. N. c., 9.

YANGUAS Juan de

Natural de Yanguas. Bachiller de Medicina. Electo colegial médico en la prebenda de Santillana el 4 de mayo de 1492 (M). Licenciado y doctor en Medicina. Más tarde médico de Corte con gran salario. N. c. 38.

SANTO DOMINGO, Lope de

Natural de Santo Domingo de la Calzada. Bachiller de Medicina. Ingresó en el Colegio el 7 de marzo de 1494. Licenciado en Medicina. No estuvo seis años en el colegio (M). N. c., 45. 
PREXANO, Fernando de

Natural de Préjano. Bachiller en Teología. Ingresó en el Colegio el 9 de febrero de 1500 (T). Hombre robusto y de gran estatura supo bien la lengua hebraica. Llevó la Cátedra de Prima de Teología y fue maestro de Teología. Jubiló su cabeza muchos años antes que muriese. Era hombre muy Ilano y apacible, pero muy desinteresado. Tuvo mucha renta. Murió en 1541 y está enterrado en la iglesia parroquial de San Francisco de Valladolid. Donó al Colegio los libros que tenía, que son todos los que están en la librería de lengua hebrea, y otros muchos de otras lenguas. N. c. 61.

\section{ESCUDERO, Diego de}

Natural de Viguera. Bachiller de Cánones. Ingresó en el Colegio el 4 de julio de 1509 (C). Doctor en Cánones. No aceptó un puesto de consejero del Consejo de la Inquisición "porque tenía dada palabra de casarse". Catedrático de Vísperas de Cánones. Oidor de Granada (1517); oidor de Valladolid (1526); consejero Real (1533); tesorero mayor de Calatrava y consejero secreto de la Cámara (1545). Partió en 1548 a Flandes con el príncipe Felipe. Participó en la redacción de la Novísima Recopilación como consta en su prólogo antiguo. Murió en Igualada en agosto de 1551 viniendo de Alemania con el mencionado príncipe. N. c., 96.

VERGARA, Juan de

Natural de La Loza, aldea de Peñacerrada. Ingresó en el Colegio el 10 de marzo de 1535 (T). Edad, 30. Se licenció en Teología. En abril de 1544 salió por visitador del obispo de Málaga "y por algunas causas que le movieron le dejó, y por la mucha necesidad que esta Santa Casa le vio, le sustentó casi un año, como si estuviera con el hábito y este tiempo le procuraron los colegiales, que estaban en la visita del obispo de Pamplona, pongo aquí esta menudencia porque los que sucedieren en la Casa, entiendan que no es cosa nueva socorrer a las necesidades de los colegiales, dieronle también otras cosas, muy necesarias para autorizar su persona, y lo mismo hoy que se había hecho antes con otros, diole un beneficio que rentaba ciento y cincuenta ducados, antes que llegase a su obispado. Nunca tubo más que este beneficio". Murió por junio de 1584. N. c., 162.

VALDERO, Juan

Natural de Alfaro. Ingresó en el Colegio el 24 de febrero de 1537. Edad, 34. Maestro de Teología. Catedrático de Biblia, el segundo que hubo en esta Universidad. En 1546 fue nombrado canónigo de Sevilla, cuando sólo le faltaban unos días por cumplir nueve años en el Colegio. Escribió Canciones Sacras. Dejó al Colegio un portapaz dorado con su nombre a la espalda. Murió en enero de 1553. N. c., 167. 


\section{MARTÍN, Diego}

Natural de Santa Coloma. Ingresó en el Colegio el 23 de septiembre de 1545 (C). Edad, 34. Bachiller canonista. Primeramente y durante dos años y medio colegial en el Colegio de Santa María de Salamanca. En este de Santa Cruz obtuvo licencia en Cánones, una catedrilla de Decretales, llevó la de Clementinas y la cátedra de Decretales (1551). Salió por octubre de 1552 con Pedro González de Mendoza, hijo del duque del Infantado, por letrado suyo, siendo reelegido en 1553 por otros ocho años más. Desempeñó también un puesto de provisor de Francisco de Navarra, obispo de Badajoz. Murió en Valencia por febrero de 1557. N. c., 190.

\section{AZTIGUIETA, Tomás}

Natural de Manzanos. Bachiller. Capellán. Ingresó en el Colegio el 10 de agosto de 1556 siendo también colegial del de Santo Tomás de Salamanca (C). Edad, 27. Salió por provisor del doctor Pedro Ponce de León, obispo de Plasencia, habiéndose graduado en Cánones. Por abril de 1567 fue prior y maestro de escuela en Coria, obteniendo un cargo en la Inquisición de Sevilla y una plaza en dicho consejo en enero de 1575. En junio de 1582 fue nombrado consejero de la Comisaría General de Cruzada con retención de su plaza. Murió en Madrid el 26 de junio de 1585. N. c., 216.

\section{CAMPORREDONDO, Juan de}

Natural de San Pedro de Yanguas. Edad, 26. Llevó, después de tres meses en el Colegio, la Cátedra de Código "sin tener opositor por no atrevérsele". Se licenció y doctoró en Cánones por esta universidad en 1572 y en 1574 fue su rector. Por diciembre de 1575 llevó la Cátedra de Digesto Viejo, por febrero de 1577 la de Vísperas de Cánones y al año siguiente la de Prima de Leyes, después ejerció de abogado por la Audiencia de Valladolid y como juez de los bienes confiscados por la Inquisición. En 1593 le concedieron la fiscalía de la Audiencia vallisoletana pero no la aceptó. En 1598, después de haberse jubilado de su Cátedra de Prima, le dieron plaza de oidor de Galicia, que también rehusó. Murió por febrero de 1602: “con gran sentimiento de todos por ser hombre de grandes prendas y que su Majestad echaba mano del para cosas mayores, habiéndosele hecho merced de la fiscalía del Consejo Real, un poco antes de que muriese". N. c., 251.

RUEDA, Martín de

Natural de Santurde. Ingresó en el Colegio el 6 de julio de 1578 (T). Edad, 27. Era de mediana disposición; colegial en el Colegio de Sigüenza y catedrático de Filosofía. El 29 de abril ocupó una cátedra de Artes, por octubre de 1582 la magistral de Ciudad Rodrigo y por septiembre de 1593 le concedieron, en la misma iglesia, otro canonicato más rico. Murió en 1599. N. c., 275. 


\section{MARTÍNEZ PLAZA, Felipe}

Natural de Sotés. Ingresó en el Colegio el 2 de julio de 1593 siendo colegial de Sigüenza (T). Edad, 29. Por julio de 1594 llevó por oposición la cátedra de Durando. Murió por octubre de 1596, "en el colegio dejó gran estima por que era muy honrado hombre y muy virtuoso y de muy buen seso". N. c., 309.

\section{ARGÁIZ, Pedro}

Natural de Arnedo. Ingresó en el colegio el 17 de mayo de 1638 siendo colegial de Sigüenza (T). Edad, 27. Por diciembre de 1641 llevó la penitenciaria de Santo Domingo de la Calzada y por agosto de 1642 la magistral de Burgos. En septiembre de 1652 se le concedió el obispado de Cartagena de las Indias, cargo que rehusó. Murió por mayo de 1658. N. c., 419.

\section{CASTEJÓN, Martín}

Natural de Alfaro. Ingresó en el Colegio el 1 de mayo de 1649. Edad, 26. Por abril de 1650 llevó la cátedra de Decretales y la de Código; por mayo de 1651 salió fiscal de la Inquisición de Zaragoza y en junio de 1653, inquisidor de ella. Por junio de 1662 fue nombrado presidente de la Inquisición de Valladolid y en octubre de 1663 inquisidor de la Suprema. Murió por septiembre de 1676. Dejó una fuente de plata al Colegio. N. c., 431.

\section{GONZÁLEZ DE TEJADA, Juan}

Natural de Ausejo. Ingresó en el Colegio por abril de 1645. Edad, 27. En agosto de 1652 fue nombrado fiscal de la Inquisición de Valencia y en 1657 su inquisidor. Murió en abril de 1675. N. c., 441.

\section{SAN CLEMENTE, José de}

Natural de Casalarreina. Ingresó en el Colegio en diciembre de 1650. Edad, 28. Llevó la cátedra de Instituta (1655); Código (1656); Clementinas y Digesto Viejo (1657); Sexto (1659) y luego la de Vísperas de Leyes, por agosto la de Decretos y por mayo la de Prima de Cánones (1662). Rector en propiedad de la Universidad de Valladolid. En mayo de 1665 se le concedió una plaza de hijosdalgo de Granada y oidor en la misma Audiencia (1670); oidor del Consejo de Hacienda (1677); oidor del Consejo de Castilla (1678) y del Consejo de la Inquisición (1683). Murió el 26 de junio de 1692. N. c., 448.

\section{GONZÁLEZ DE TEJADA, José}

Natural de Gallinero. Ingresó en el Colegio en febrero de 1667 siendo colegial del Colegio de Alcalá. Edad, 30. Escritor. En marzo de 1668 Ilevó la magistral de Palencia y después la de Santo Domingo de la Calzada. En enero de 1686 se le concedió el obispado de Durango en Indias, que rehusó. Después, el cardenal de Toledo, Portocarrero, le dio una prebenda en la misma iglesia 
que aceptó. Murió en Toledo en noviembre de 1704. Dejó al Colegio 50 ducados para una misa. Escribió un libro titulado Abraham de la Rioxa, que se reduce a la vida y milagros de Santo Domingo de la Calzada con un catálogo de todos los obispos de Calahorra y la Calzada al final. N. c., 490.

\section{MELGAR Y MOREDA, Gaspar}

Natural de Santo Domingo de la Calzada. Ingresó en el Colegio en septiembre de 1668. Edad, 41. En junio de 1670 Ilevó la penitenciaria de Osma. Murió en septiembre de 1683. N. c., 495.

\section{SAN VICENTE Y VELANDÍA, Alonso de}

Natural del Villar de Alfaro. Ingresó en el Colegio el 1 de noviembre de 1679. Edad, 21. Llevó la cátedra de Decretales y se puso el hábito de Calatrava. En enero de 1685 logró la de Clementinas; en 1685, Digesto Viejo; en 1688, Sexto y al poco una plaza de Gradas de Sevilla y alcalde del crimen de la Chancillería de Valladolid. Murió el 2 de enero de 1689. N. c., 500.

ANGULO, Andrés de

Natural de Navarrete. Ingresó en el Colegio el 28 de diciembre 1670, siendo colegial del de Alcalá. Edad, 28. Se le concedió plaza de fiscal de la Inquisición de Valladolid (1674) y después plaza entera (1676). Nombrado inquisidor de SeviIla (1677); se le concedió la maestría de Salamanca (1679); la presidencia de la de Granada (1682); después consejero del Consejo de Castilla (1683) y el obispado de Segovia (1685). Murió en esta ciudad en agosto de 1688. N. c., 502.

\section{MEDRANO Y EHÁUZ, Pedro Antonio}

Natural de Logroño. Ingresó en el Colegio por 1669 (C). Llevó la cátedra de Decretales (1685); la de Código (1686) y la de Sexto (1690). Hizo de sustituto en la plaza de juez mayor de Vizcaya de la Chancillería de Valladolid (octubre 1686-marzo 1687) y, por segunda vez (abril 1688-febrero 1689). Sustituyó las dos fiscalías de esta Chancillería (1689) y en abril de 1690 realizó la tercera sustitución, Ilevando al mismo tiempo la cátedra de Vísperas de Leyes. Se le concedió una plaza de oidor de la Chancillería de Valladolid (1695); la regencia de la de Navarra (1702), obteniendo poco después una plaza del Consejo de Órdenes y el hábito de Alcántara (1705). Murió en diciembre de 1721. N. c., 508.

\section{MORAL Y TEXADA, Pablo}

Natural de Navarrete. Edad, 23. Obtuvo un canonicato en la Iglesia de Santo Domingo de la Calzada. Llevó la primera oposición de cátedra de Instituta (1685); fue nombrado visitador general de este obispado (1688); provisor y al mismo tiempo llevó la cátedra de Clementinas (1691); la de Vísperas de Leyes y la fiscalía de la Inquisición de Granada (1692), obteniendo la plaza entera en 
1694. Nombrado inquisidor de Toledo "por probarle mal el temple de Granada" (1700); fiscal de la Suprema (1704) e inquisidor (1705). Murió en Navarrete en 1716 . N. c., 522.

\section{CASTEJÓN, Martín}

Natural de Alfaro. Ingresó en el Colegio el 27 de febrero de 1678 (T). Edad, 21. Caballero de la Orden de Calatrava. Abandonó el Colegio y se casó con su prima hermana, hija única del marqués del Castillo. Murió el 19 de octubre de 1684. N. c., 527.

\section{SÁNCHEZ SALVADOR, Marcos}

Natural de Lumbreras. Ingresó en el Colegio en 1681 (C). Edad, 24. Dos veces rector del Colegio. Llevó la cátedra de Código más Antigua (1691); la de Digesto Viejo y la de Decreto (1692) y la de Prima de Leyes (1696). Fue nombrado juez mayor de Vizcaya (1697) y tomó también el hábito de Calatrava; obtuvo plaza de oidor en la Chancillería de Valladolid (1700); alcalde de Casa y Corte (1703); consejero de Castilla (1706); presidente de la Sala de Alcaldes de Casa y Corte (1715) y camarista de la Cámara de Castilla (1723). Rector de la Universidad de Valladolid, por el claustro, en vacante del señor Omaña. Después lo ejercitó por elección de los señores del Consejo. N. c, 537.

\section{BERGADO, Antonio}

Natural de Briones. Ingresó en el Colegio el 10 de julio de 1681. Edad, 23. Había sido provisor de Málaga, colegial de los Verdes de Alcalá e inquisidor de Valencia. Fue nombrado inquisidor de Cuenca (1684) y canónico de la Santa Iglesia de Toledo (1694). Poco después se le dio el arcedianato titular de Calahorra abandonando la prebenda de Toledo. Murió por diciembre de 1704. N. c., 543.

\section{ÁLVAREZ, Baltasar}

Natural de Cervera. Ingresó en el Colegio el 16 de marzo de 1686. Edad, 29. En dicho mes le tocó la suerte de ser rector en sustitución y en 1687 lo fue en propiedad. Después se le hizo merced de la primera plaza del crimen que quedase vacante en la Chancillería de Valladolid, yendo a servir finalmente a la de Granada (1691) de donde fue también oidor (1698). Regresó a Madrid al ser nombrado alcalde de Casa y Corte (1713), consejero de Hacienda (1714), corregidor de Logroño (1716) y de Cuenca (1720). Murió jubilado en su tierra. N. c., 554.

\section{BRETÓN, Justo}

Natural de Arnedo. Ingresó en el Colegio el 16 de marzo de 1686. Edad, 23. Llevó la cátedra de Instituta (1697). Murió en noviembre de 1698. Se enterró en la capilla del Colegio del Carmen Descalzo. Dejó al Colegio un legado de doscientos ducados. N. c., 556. 
IBÁÑEZ, Jerónimo

Natural de Logroño. Ingresó en el Colegio el 18 de diciembre de 1686 (J). Edad, 23. Fiscal del Tribunal de la Inquisición de Palma de Mallorca (1699); sentó plaza de inquisidor de Logroño (1702). Murió en 1717. N. c., 558.

\section{PUEYO Y CAMARGO, Martín}

Natural de Alfaro. Ingresó en el Colegio el 24 de septiembre de 1688 (C). Edad, 23. Le tocó ser rector de este Colegio de Santa Cruz en 1690 y 1695. En agosto de 1699 fue nombrado fiscal con voto en Canarias. Se encontraba en Ágreda recuperándose de sus achaques por agosto de 1705 cuando murió. Dejó un legado al Colegio de 400 ducados. N. c., 563.

DÍEZ OROZCO, Juan

Ingresó en el Colegio el 14 de septiembre de 1695 (T). Edad, 35. Había sido colegial de San Antonio de Sigüenza, catedrático de Artes, graduado en ellas, y en Teología. Le tocó ser rector (1698) y llevó la Cátedra de Artes en la Universidad de Valladolid (1699). Obtuvo la canonjía magistral de Sigüenza (1700). N. c., 576.

\section{ANGULO Y VELASCO, Pedro}

Natural de Navarrete. Ingresó en el Colegio con beca cantada. Edad, 21. Rector del Colegio (1701); obtuvo la cátedra de Instituta (1713); oidor en Palma de Mallorca (1716); oidor del Consejo de Navarra (1724) y plaza de alcalde de Casa y Corte (1732). Tomó hábito de Calatrava. Murió a finales de 1732. N. c., 584.

TOBALINA, Blas

Natural de Ollauri. Ingresó en el Colegio el 6 de octubre de 1698 (T). Llevó la cátedra de Artes (1701) y la canonjía penitenciaria de la Santa Iglesia de Burgos (1702). N. c., 589.

MANZANARES, Juan de

Natural de Alesanco. Ingresó en el Colegio el 8 de diciembre de 1701 (T). Edad, 27. Era por entonces ya colegial de San Antonio de Sigüenza, catedrático de Artes, doctor en teología por dicha Universidad y examinador sinodal de aquel obispado. Rector del Colegio (1704), en agosto Ilevó la cátedra de Artes en la Universidad de Valladolid. Llevó en 1705 la prebenda penitenciaria de Santo Domingo de la Calzada. N. c., 598.

\section{TEJADA Y PORRAS, Andrés}

Natural de Santo Domingo de la Calzada. Ingresó en el Colegio el 22 de diciembre de 1705 (cantada). Edad, 21. Fue elegido rector por ausencia el 15 de septiembre de 1707. Murió el 31 de diciembre de 1718. N. c., 615. 


\section{SALAZAR Y CASTEJÓN, Francisco}

Natural de Logroño. Ingresó en el Colegio el 27 de septiembre de 1706 (cantada). Edad, 21. Fue rector en 1708. Obtuvo plaza de alcalde del crimen de la ciudad de Lima (1720). Desde allí envió, en 1729, 100 doblones al Colegio: 50 para la librea y los otros para lo que fuere muy preciso. N. c., 616.

\section{DURO DEL SAR, José}

Natural de Albelda. Ingresó en el Colegio el 10 de octubre de 1707 (T). Edad, 29. Colegial del de los Teólogos de Alcalá de Henares. Licenciado en Artes por aquella Universidad, bachiller en Teología habiendo ya cursado cuatro años para el grado de doctor. Obtuvo plaza de rector en propiedad en mayo de 1709 y en junio de ese mismo año Ilevó la cátedra de Artes de la Universidad de Valladolid. En agosto de 1713 el Consejo le concedió la cátedra de Durando. En octubre de ese año llevó además la prebenda magistral de la Santa Iglesia de Cuenca -de donde es colegial actual- y en concurso de seis canonjías de oficio de diversas catedrales: cuatro colegiales de esta santa casa, otro de San Bartolomé y otro colegial del Arzobispado. N. c., 619.

\section{SÁNCHEZ SALVADOR, Francisco Antonio}

Natural de Laguna. Ingresó en el Colegio el 8 de enero de 1719. Edad, 21. Rector del Colegio (1726) y catedrático de Instituta (1732). N. c., 648.

\section{SÁNCHEZ CABEZÓN, Francisco Javier}

Natural de Treguajantes. Ingresó en el Colegio el 7 de noviembre de 1719 (T). Edad, 33. Años antes fue también colegial teólogo en el Colegio de Alcalá de Henares y tenía el curato de Fuencarral. En mayo de 1721 obtuvo la cátedra de Artes de primera oposición. En 1723 Ilevó la lectoral. N. c., 650.

\section{MANGADO CLAVIJO, Diego}

Natural de El Redal. Ingresó en el Colegio el 5 de noviembre de 1720 (cantada). Edad, 21. En 1725 obtuvo la cátedra de las Charcas que permutó por unos beneficios. En 1729 fue nombrado fiscal del Consejo Supremo de la Inquisición de México, lugar donde murió. N. c., 651.

SAMANIEGO Y SALAMANCA, Joaquín de

Natural de Logroño. Ingresó en el Colegio el 18 de octubre de 1722 (cantada). Edad, 31. En 1729 fue nombrado inquisidor de Canarias y luego de Mallorca, Cuenca y Granada. N. c., 656.

MOREDA, Felipe

Natural de Navarrete. Ingresó en el Colegio el 25 de septiembre de 1726 (T). Edad, 22. Por San Miguel de 1728 le tocó ser rector y el 19 de mayo de 1730 
Ilevó la rectoral de Osma. En septiembre de 1760 fue nombrado prior de dicha iglesia. N. c., 666.

\section{SÁNCHEZ SALVADOR, Manuel Domingo}

Natural de Lumbreras. Ingresó en el Colegio el 21 de junio de 1727 (C). Edad, 21. Obtuvo la cátedra de Decretales de la Universidad de Valladolid (1742); la de Código Antiguo (1744); la de Clementinas (1746) y la de Decretales Mayores (1747). En 1748 fue nombrado alcalde mayor de la Audiencia de Oviedo; oidor del Consejo de Navarra (1758); honores de alcalde de Corte "por haber concurrido como diputado de Soria a la Jura de S. M. y Príncipe de Asturias" (1760) y alcalde de Casa y Corte en propiedad (1765). Murió en enero de 1767. A su muerte legó al Colegio "una completa colección de libros de 60 tomos de diversos autores todos relativos al progreso, decadencia y extrañamiento de los regulares de la Compañía de Jesús desde sus principios y nacimiento en España, Portugal, Francia, Paraguay y China". N. c., 668.

PÉREZ, Francisco Javier

Natural de Autol. Ingresó en el Colegio el 24 de diciembre de 1728 (T). Edad, 26. Obtuvo una cátedra de Artes (1733), después llevó la magistral de esta iglesia (1735); la cátedra de Suárez (1745); la de San Anselmo (1746); la de Santo Tomás (1747) y la cátedra de Teología de Durando graduándose como rector en esta Universidad (1749). En agosto de 1755 fue nombrado obispo de Teruel. Murió en 1757. N. C., 672.

\section{MERINO Y ROMO, Juan Antonio}

Natural de Ventas Blancas y originario de Ausejo. Ingresó en el Colegio el 23 de noviembre de 1729. Edad, 24. Rector del Colegio (1732). Inquisidor de Mallorca (1736); de Zaragoza (1742) y de Corte (1760); fiscal de la Suprema (1765) y después consejero de la misma. Murió en Madrid en 1780. Dejó al Colegio cien ducados. N. c., 674.

\section{MURILLO Y ARGÁIZ, Manuel}

Natural de Murillo de Río Leza. Ingresó en el Colegio el 3 de diciembre de 1730 (T). Edad, 25. Llevó la magistral de Burgos (1732). Rector en propiedad (1731-1732); llevó la rectoral de Toledo (1733). Fue nombrado obispo de Segovia en 1752, cargo al que renunció en 1765 . Después se retiró a Murillo. Dio a esta casa 1.000 pesos para una colgadura de la capilla, pintó la bovedilla y doró la media caña "como hoy día se ve". Todas estas obras se realizaron en abril de 1764. N. c., 677. 


\section{SALAZAR Y BUSTAMANTE, FrancisCo}

Natural de Baños de Río Tobía. Ingresó en el Colegio el 23 de diciembre de 1733. Edad, 23. Rector en propiedad (1740); plaza de alcalde del crimen de la Chancillería de Valladolid (1745); alcalde de Casa y Corte (1769). Murió en Madrid el 27 de noviembre de ese mismo año. N. c., 685.

\section{SEGURA Y CASTRO, Manuel}

Natural de Torrecilla de Cameros. Ingresó en el Colegio el 18 de febrero de 1736 (T). Edad, 35. Para entonces había sido ya colegial, catedrático de Artes y rector de la Universidad de Alcalá. Fue nombrado rector en propiedad (1737) y reelegido después por haber ido a su plaza de inquisidor de Logroño el licenciado Mollinedo (1743). Llevó la penitenciaria de León (1748). Murió en abril de 1749. N. c., 690.

\section{CERECEZA, Manuel Ignacio}

Originario de Verguizas (Yanguas). Ingresó en el Colegio el 18 de junio de 1736 (beca del licenciado Salvador). Edad, 22. Rector del colegio en propiedad (1738). Obtuvo la cátedra de Instituta más antigua (1750); la de Código más antigua (1751); la de Digesto Viejo (1752) y la de Sexto (1753). Fiscal de SeviIla con consulta de la Cámara (1755) y fiscal del crimen de la Chancillería de Valladolid (1764). Se casó en febrero de 1759 con doña María del Carmen Torres Blanco y Orozco, hija del señor Torres, decano del Consejo de Órdenes. Murió en mayo de 1769. N. c., 693.

\section{CABEZÓN, José Antonio}

Natural de Treguajantes, abadía de San Prudencio. Ingresó en el Colegio el 22 de septiembre de 1742 (C). Edad, 29. Rector en propiedad del colegio (1743) y, por recomendación de su tío, obispo de Astorga (1750); Ilevó la Doctoralia de allí (1751) y recibió también el cargo de tesorero. Murió cuando iba a ser reelegido provisor. N. c., 703.

BLANCO, José Antonio

Natural de Zarzosa. Ingresó en el Colegio el 26 de septiembre de 1742 (beca del licenciado Orive). Edad, 21. Colegial de la Madre de Dios de los Teólogos de la Universidad de Alcalá. Rector en propiedad del colegio (1746); catedrático de Artes (1747). Llevó la magistral de Astorga (1749) y electo canónigo de Toledo (1762). N. c., 704.

\section{SANTA MARÍA Y SAN ROMÁN, Juan Antonio}

Natural de Muro de Cameros. Ingresó en el Colegio el 19 de octubre de 1743 (T). Edad, 26. Rector en propiedad (1747). Catedrático de Artes (1749); Ile- 
vó la lectoral de Zamora (1751); la magistral de Cuenca (1754). Dio al Colegio en 1757 veinticinco doblones. Murió en Cuenca en 1763. N. c., 706.

\section{ARGÁIZ IVARNAVARRO, Marcos}

Natural de Arnedo. Ingresó en el Colegio el 19 de octubre de 1744 (C). Edad, 21. Rector en propiedad (1749). Le hizo su provisor el obispo de Pamplona en 1750 y el señor Murillo, colegial y obispo de Segovia, le hizo arcipreste, obteniendo al mismo tiempo una cátedra de Decretales Menores, la de Código más moderno y más antiguo, rehusando una plaza de fiscal de la Inquisición de Sevilla (1754). Rector de la Universidad de Valladolid (1756); catedrático de Digesto Viejo (1758); fiscal de lo civil de La Coruña (1761) y su alcalde mayor (1767). N. c., 707.

\section{MARTÍNEZ ISUNZA SÁNCHEZ SALVADOR, Cayetano}

Natural de Lumbreras. Ingresó en el Colegio el 17 de junio de 1747 (C). Edad, 23. Llevó la penitenciaría de Calahorra (1751) y provisor de vacante (1752). Canónigo de Cuenca a consulta de la Cámara (1755) y el obispado de Ávila (1766), al que renunció. Murió el 22 de julio de 1769. N. c., 713.

VÁZQUEZ DE ACUÑA, Juan Ignacio

Natural de Logroño. Ingresó en el Colegio el 20 de septiembre de 1749 (T). Edad, 24 años. En 1752 Ilevó la penitenciaria de Santo Domingo de la Calzada. N. c., 717.

\section{LÓPEZ MONTENEGRO, Pedro Pablo}

Natural de Villoslada de Cameros. Ingresó en el Colegio el 31 de agosto de 1750 (C). Edad, 21. Rector en propiedad (1751) y vicerrector (1761). Obtuvo la Cátedra de Instituta Antigua y el rectorado en propiedad de la Universidad de Valladolid (1762); la de Código menos antiguo (1763); la de Código más antiguo (1766) y la de Clementinas (1767). N. c., 720.

MIRANDA Y SALINAS, Juan

Natural de Salinas. Ingresó en el Colegio el 15 de julio de 1751 (C). Edad, 21. Fue nombrado sustituto de juez mayor de Vizcaya (1762) y Rector de la Universidad de Valladolid (1766). Obtuvo la Cátedra de Instituta más antigua (1767) graduándose en Leyes en octubre de 1769. N. c., 722.

SÁENZ DE SANTA MARÍA, José Antonio

Natural de Muro de Aguas. Ingresó en el Colegio el 12 de noviembre de 1751 (C). Edad, 25. Llevó la Doctoral de Zamora (1757); prior de esa diócesis (1761) y después una canonjía en Toledo, vicario general y arcediano de Madrid (1764). N. c., 723. 


\section{GARCÍA ROLDÁN, Tomás}

Natural de Santa Coloma. Ingresó en el Colegio el 8 de marzo de 1752 (T). Edad, 24. Rector en propiedad (1753) y canónigo de Calahorra en 1758. N. c., 725.

YANGUAS, Baltasar

Natural de Sojuela. Ingresó en el Colegio el 21 de diciembre de 1792 (C). Edad, 21. En septiembre de 1755 fue nombrado rector en propiedad en dicho colegio. N. c., 730.

\section{EULATE, Antonio}

Natural de Salvatierra. Ingresó en el Colegio el 24 de febrero de 1753 (C). Edad, 21 años. Después fue nombrado alcalde del crimen de Granada. N. c., 731.

\section{CEBALLOS MARÍN, Andrés}

Natural de Cirueña. Ingresó en el Colegio el 2 de octubre de 1754 (T). Edad, 24. Rector en propiedad (1757). Llevó la rectoral de Osma (1761) y un canonicato en Toledo en donde se le dio la abadía de San Vicente, dignidad de aqueIla iglesia (1772). N. c., 735.

MARTÍNEZ BASTIDAS, José

Natural de San Vicente de la Sonsierra. Ingresó en el Colegio el 23 de noviembre de 1755 (C). Edad, 24. N. c., 738.

\section{GARCÍA DEL VALLE, Lorenzo}

Natural de Viguera de Abajo. Ingresó en el Colegio el 12 de mayo de 1756 (C). Edad, 22. Rector en propiedad (1759). El 1 de mayo de 1764 tomó el hábito de monje en el Monasterio de Nuestra Señora de la Huerta, poniéndose el nombre de Francisco Agustín. Murió en Salamanca el 16 de octubre de 1767 estudiando teología. Tomó la casulla el día de la conversión de San Agustín. N. c., 739.

HERAS Y VALLE, Benito de las

Natural de Alfaro. Ingresó en el Colegio el 6 de agosto de 1760 (C). En noviembre de 1760 Ilevó la penitenciaria de Astorga. N. c., 749.

\section{CRESPO PONCE DE LEÓN, Joaquín}

Natural de Badarán. Ingresó en el Colegio el 4 de septiembre de 1761 (T). Edad, 30. En febrero de 1763 Ilevó la penitenciaria de Osma. N. c., 758.

RÍO Y CAMPORREDONDO, Franciso Enrique del

Natural de Ribafrecha. Ingresó en el Colegio el 13 de mayo de 1762 (C). Edad, 36. Llevó la doctoral de Santo Domingo de la Calzada (1763). Murió en 1778. N. c., 760. 


\section{GARCÍA DE TEJADA CERECEZA, Francisco}

Natural de Ortigosa de Cameros. Ingresó en el Colegio el día 24 de diciembre de 1762 (C). Edad, 28. Rector en propiedad (1766). N. c., 764.

\section{MARRÓN GÓMEZ DE ELGUETA, José}

Natural de Cordovín. Ingresó en el Colegio el 2 de mayo de 1763 (C). Edad, 26. Llevó la penitenciaria de Lugo (1766) y luego la de Burgos en donde también desempeñó el cargo de prior. N. c., 766.

GARCÍA Y MIRANDA, Benito

Natural de Préjano. Ingresó en el Colegio el 14 de octubre de 1763 (C). Edad, 19. Rector en propiedad en dicho colegio (1767). En julio de 1768 el obispo de Jaén, Benito Marín, le nombró canónigo de aquella ciudad. N. c., 770.

SALCEDO Y SOMODEVILLA, Modesto

Natural de Santo Domingo de la Calzada. Ingresó en el Colegio el 10 de diciembre de 1763 (C). Edad, 21. N. c., 771.

GALINDO, Juan Manuel

Natural de Mansilla de Canales. Ingresó en el Colegio el 9 de noviembre de 1764 (C). Edad, 21. Rector en propiedad (1770). N. C., 775.

FERNÁNDEZ ANGULO, Manuel

Natural de Fonseca. Ingresó en el Colegio el 13 de noviembre de 1770 (C). Edad, 25 años. N. c., 782.

NARCISO PORRES, Juan

Natural de Cervera del Río Alhama. Ingresó en el Colegio el 29 de octubre de 1777 (T). Edad, 23. Rector en 1778. N. c., 792. 